\title{
OXIDATION AND CHARACTERIZATION OF ACTIVE CARBON AG-5
}

\author{
Tatiana Goreacioc
}

\author{
Institute of Chemistry of Academy of Sciences of Moldova, 3, Academiei str., Chisinau MD-2028, Republic of Moldova \\ Institute of Ecology and Geography of Academy of Sciences of Moldova, 1, Academiei str., \\ Chisinau MD-2028, Republic of Moldova, \\ e-mail: araputatiana@yahoo.com
}

\begin{abstract}
The surface chemistry of the commercial active carbon AG-5 has been modified by oxidation with concentrated nitric acid. The structural changes caused by oxidative treatment were estimated on the basis of nitrogen adsorption-desorption isotherms and thermal analysis. Boehm titration method and infrared spectral analysis have been used in order to evaluate surface chemistry characteristics of active carbon samples. After oxidation process the amount of total acidic groups on oxidized active carbon surface (AG-5ox) increases by about 6 times in comparison with unmodified sample (AG-5). The concentration of the acidic groups on the oxidized active carbon surface (AG-5ox) was in the following order: strong acidic $>>>$ weak acidic $>$ phenolic.
\end{abstract}

Keywords: active carbon, oxidation, surface properties, thermal analysis, infrared spectroscopy.

Received: August 2014/ Revised final: October 2014/ Accepted: October 2014

\section{Introduction}

For the treatments of drinking and waste waters, packed beds of granular activated carbon are frequently used. The type of contaminant which will be adsorbed and the adsorption/removal efficiency of the active carbons are strongly dependent on their both porous structure and surface chemistry [1-4]. Therefore, the surface chemical modification of active carbons is of great interest in order to produce materials for specific applications. This modification has been mainly carried out by oxidative methods, producing a more hydrophilic structure with a large number of oxygencontaining groups [5]. Various reagents have been used as oxidants: nitric acid, hydrogen peroxide, sodium hypochlorite, permanganate, transition metals etc. [5-10]. A review of the literature concerning oxidation of the active carbons shows, that using nitric acid as oxidizing agent provides strong acidic functional groups on the carbon surface [6, 11-13].

In order to minimize operational problems during the water treatment processes, attention must be given to the size of the granular active carbon particles. The large particles have a small external surface area and long internal diffusion path lengths [14]. This reduces the mass transfer velocity, resulting in long adsorption/removal processes of pollutants from waters.

The aim of this work was to modify the surface chemistry of the commercial granular active carbon AG-5, using the concentrated nitric acid as oxidizing agent. In order to characterize unmodified and oxidized active carbon samples, the standard test methods for evaluation of physical properties (particle size distribution and bulk density), physical-chemical characteristics (elemental analysis, thermal analysis, nitrogen adsorption measurements) and surface chemistry characteristics (pH of surface, Boehm titration method and IR spectral analysis) have been used.

\section{Experimental \\ Materials}

In this study commercially available granular activated carbon AG-5 (GOST 20777-75) has been used. Activated carbon AG-5 is obtained from pit coal by steam activation representing granules of cylindrical shape [15]. All the chemical reagents used in this study were of analytical grade.

\section{Sample oxidation method}

The oxidation was carried out as follows: the solution of concentrated nitric acid (63\%) was added to $400 \mathrm{~g}$ of granular active carbon AG-5 (at a ratio of solid:liquid of 1:3), which was placed in the glass flask on the water bath. The flask was connected with reflux condenser ended with absorption bulb filled with the $\mathrm{NaOH}$ solution. The carbonnitric acid mixture was kept at the temperature of $95^{\circ} \mathrm{C}$ for $8 \mathrm{~h}$. The released nitrogen oxides were absorbed in the absorption bulb. After finishing the oxidation process the mixture was cooled and decanted. The humic acids formed during oxidation processes have been removed with $1.0 \mathrm{~N}$ solution of $\mathrm{KOH}$. After removal of humic acids the oxidized active carbon sample has been treated with $1.0 \mathrm{~N}$ solution of $\mathrm{HCl}$ in order to neutralize residual $\mathrm{KOH}$ and to obtain the $\mathrm{H}^{+}$form of oxidized active carbon.

Afterwards, the oxidized sample was extensively washed with distilled water until chlorine ions have not been detected in the washing water, dried at $110 \pm 5^{\circ} \mathrm{C}$ and labelled as AG-5ox.

\section{Characterization methods}

Prior characterization measurements the active carbon samples were dried at $110 \pm 5^{\circ} \mathrm{C}$ for $3 \mathrm{~h}$. 


\section{Physical characteristics}

Particle size is an important property influencing the flow characteristics, adsorption kinetics and catalytic behaviour of granular activated carbon layers. The granular active carbon samples were separated according to particle size using a set of standard sieves with decreasing size opening (in $\mathrm{mm}$ ). The results are given in weight percent for those particles between different sieves expressed as particle size [16].

The bulk density is defined as the mass of a unit volume of the sample in air, including both the pore system and the voids between the particles. The bulk density $\left(D_{b}\right)$ is given in $\mathrm{g} / \mathrm{cm}^{3}$ and determined by Eq.(1) [16]:

$$
D_{b}=\frac{m}{V}
$$

where, $m$ - mass of the dry sample in g;

$V$ - volume of the sample, measured under test condition in $\mathrm{cm}^{3}$.

\section{Physical-chemical characteristics}

Elemental analysis $(\mathrm{C}, \mathrm{H}, \mathrm{N})$ was carried out by the Elemental Analysis group of the Institute of Chemistry of the Academy of Sciences of Moldova.

The content of metals was determined by atomic absorption spectroscopy (AAS-1N).

The surface area, pore volumes and pore size distributions of the carbons were performed on a surface area analyzer (Autosorb 1-MP) through $\mathrm{N}_{2}$ adsorption-desorption at $77 \mathrm{~K}$ after outgassing the samples at $250^{\circ} \mathrm{C}$ to a residual vacuum $10^{-5} \mathrm{~Pa}$ [17]. Surface area $\left(S_{B E T}\right)$ was measured by the BET (Brunauer-Emmet-Teller equation) method. Pore size distribution was determined by the Non-Local Density Functional Theory (NLDFT) method assuming slit pore geometry. The total pore volume $\left(V_{\text {total }}\right)$ was deduced from the manufacturer's software [18]. Micropore volume $\left(V_{\text {micro }}\right)$ was calculated using Dubinin Radushkevich (DR) method. Mesopore volume $\left(V_{\text {meso }}\right)$ was determined by the subtraction of the $V_{\text {micro }}$ from the $V_{\text {total }}$.

Thermal analysis measurements were performed using a Derivatograph Q-1000 analyzer. The samples were

heated from room temperature up to $1000^{\circ} \mathrm{C}$ in air at a heating rate of $10^{\circ} \mathrm{C} / \mathrm{min}$.

\section{Surface chemistry characteristics}

The $\mathrm{pH}$ of the active carbon surface has been evaluated by determination of $\mathrm{pH}$ value of active carbon suspension ( $0.4 \mathrm{~g}$ of dried sample/20 $\mathrm{mL}$ of distilled water) equilibrated for $24 \mathrm{~h} \mathrm{[19].}$

The quantification of the surface functional groups have been done by selective neutralization technique of Boehm [20]. According to this method, carbon sample (0.5g) was equilibrated with $50 \mathrm{~mL}$ of each of three bases $0.05 \mathrm{~N} \mathrm{NaHCO}, \mathrm{Na}_{2} \mathrm{CO}_{3}, \mathrm{NaOH}$, sealed and shaken for $72 \mathrm{~h}$, and then $10 \mathrm{~mL}$ of each filtrate was back-titrated with $0.05 \mathrm{~N} \mathrm{HCl}$. The surface concentrations of each acidic groups: strong-carboxyl, weak-carboxyl and phenolic; have been determined by differences between the amounts reduced by each of the bases [11]. The total basic surface oxides have been determined with a similar titration technique using $0.05 \mathrm{~N} \mathrm{HCl}$ and back-titrating with $0.05 \mathrm{~N} \mathrm{NaOH}$. Titrations have been done using automated titrator TitroLine ${ }^{\circledR} 6000$ (SI Analytics, Germany).

The concentrations of surface acidic groups $\left(N^{A}\right.$, meq/g) have been calculated by Eq.(2):

$$
N^{A}=\frac{\left(C_{0}-C_{e}\right) V}{m}
$$

where, $C_{0}$ and $C_{e}$ are initial and equilibrium concentrations of bases $\mathrm{NaHCO}_{3}, \mathrm{Na}_{2} \mathrm{CO}_{3}, \mathrm{NaOH}$;

$V$ - volume of bases added to active carbon sample, in $\mathrm{mL}$;

$m$ - mass of active carbon sample, in $\mathrm{g}$.

The quantity of the basic functional groups ( $N^{B}$, meq/g) has been calculated by Eq.(3):

$$
N^{B}=\frac{\left(C_{0}-C_{e}\right) V}{m}
$$

where, $C_{0}$ and $C_{e}$ are initial and equilibrium concentrations of $\mathrm{HCl}$;

$V$ - volume of $\mathrm{HCl}$ added to active carbon sample, in $\mathrm{mL}$;

$m$ - mass of active carbon sample, in g.

The Fourier Transform Infrared spectra (FTIR) of the active carbons were recorded in the range $400-4000 \mathrm{~cm}^{-1}$ using a Fourier Transform Infrared Spectrometer (PerkinElmer, Spectrum 100, USA). Prior to spectral analysis the samples were dried and the dilutions in $\mathrm{KBr}$ have been used (0.15wt\%).

\section{Results and discussion \\ Physical characteristics}

The particle size distribution evaluated by sieve analysis is presented in Figure 1. For both samples, initial granular active carbon AG-5 and modified by oxidation AG-5ox, the size fraction between 1.3 and 2.0 represents about $65 \%$ of total weight. For further experiments the size fraction between 0.8 and $2.0 \mathrm{~mm}$ was chosen. 
The bilk density has been determined only for the size fraction $0.8 \div 2.0 \mathrm{~mm}$, which was selected for further experiments. After oxidation process the bulk density of active carbon AG-5ox decreases with about $4 \%$, it can be explained by removal of soluble inorganic (ash) with nitric acid (Table 1).

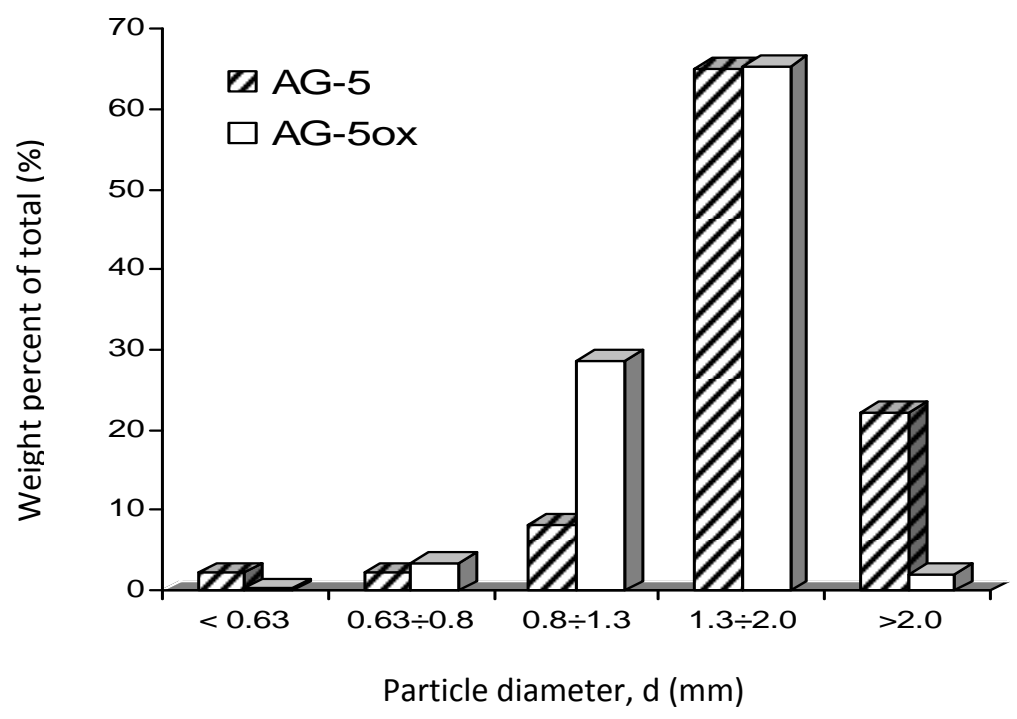

Figure 1. Weight percent of different size fractions of the initial granular active carbon AG-5 and modified by oxidation AG-5ox.

The bulk density of size fraction $0.8 \div 2.0 \mathrm{~mm}$ for initial and oxidized active carbon samples.

\begin{tabular}{lcc}
\hline Sample & Characterization & Bulk density $D_{b}, \mathrm{~g} / \mathrm{cm}^{3}$ \\
\hline AG-5 & initial & $<0.578> \pm 0.005$ \\
AG-5ox & oxidized with nitric acid & $<0.553> \pm 0.004$ \\
\hline
\end{tabular}

\section{Physical-chemical characteristics}

The elemental analysis, the metals and ash content for studied active carbon samples, are presented in Tables 2 and 3. The initial active carbon AG-5 contains about $16.6 \%$ ash, while after oxidation with nitric acid this value decreased to ca. 6\% (Table 2). Similar results have been obtained by Jaroniec et al. during oxidation of AG-5 active carbon with concentrated nitric acid [21]. After oxidation process most of the metals are removed from the active carbon sample (Table 3).

Table 2

Proximate and ultimate analyses of active carbon samples.

\begin{tabular}{ccccccc}
\hline \multirow{2}{*}{ Sample } & Ash & \multicolumn{5}{c}{ Ultimate analysis (wt\%, daf* $)$} \\
\cline { 3 - 7 } & $(w t \%)^{*}$ & $C$ & $H$ & $S$ & $N$ & $O^{* * *}$ \\
\hline AG-5 & 16.60 & 80.24 & 2.73 & 1.37 & - & 15.66 \\
AG-50x & 5.93 & 77.73 & 2.92 & - & 0.32 & 19.03 \\
\hline
\end{tabular}

${ }^{*}$ Ash content has been determined from thermo-gravimetric analysis (TGA) curve at $1000^{\circ} \mathrm{C}$

${ }^{* *}$ Determined on dry and ash free basis

${ }^{* * *}$ By difference

Analyses of mineral matters in active carbon samples.

\begin{tabular}{ccccccccccc}
\hline & \multirow{2}{*}{ Sample } & Ash & \multirow{2}{c}{ Constituents in mineral matter (wt\%) } \\
\cline { 3 - 11 } & $($ wt\%) & $\mathrm{Na}_{2} \mathrm{O}$ & $\mathrm{K}_{2} \mathrm{O}$ & $\mathrm{CaO}$ & $\mathrm{MgO}$ & $\mathrm{Fe}_{2} \mathrm{O}_{3}$ & $\mathrm{MnO}_{2}$ & $\mathrm{CuO}$ & $\mathrm{Cr}_{2} \mathrm{O}_{3}$ & $\mathrm{NiO}$ \\
\hline AG-5 & 16.60 & 0.40 & 1.49 & 1.11 & 0.41 & 5.63 & 0.04 & 0.03 & - & 0.01 \\
AG-50x & 5.93 & 0.03 & 1.08 & - & 0.01 & 0.18 & - & - & - & - \\
\hline
\end{tabular}


Nitrogen adsorption isotherms and pore size distribution curves for studied samples are shown in Figures 2 and 3. Both samples exhibit microporous structure. The porous structure parameters calculated from nitrogen adsorption isotherms are presented in Table 4. As can be seen, the values of the BET surface area $\left(S_{B E T}\right)$, total pore volume $\left(V_{\text {total }}\right)$ and micropore volume $\left(V_{\text {micro }}\right)$ slightly increase after oxidation treatment with about 14-16\% (Table 4).

The impact of nitric acid on porous structure of the active carbon AG-5 is quite different described in the literature. Some authors have been reported an increase of total pore volume after oxidation of AG-5 with nitric acid, while other authors have been presented opposite results, degradation of porous structure and decrease of structural parameters values over $50 \%[6,12,13,21]$. In our case, we suggest, the slight increase of structural parameters values after oxidation process is due to dissolution of inorganic species that may block the entrance of micropores.

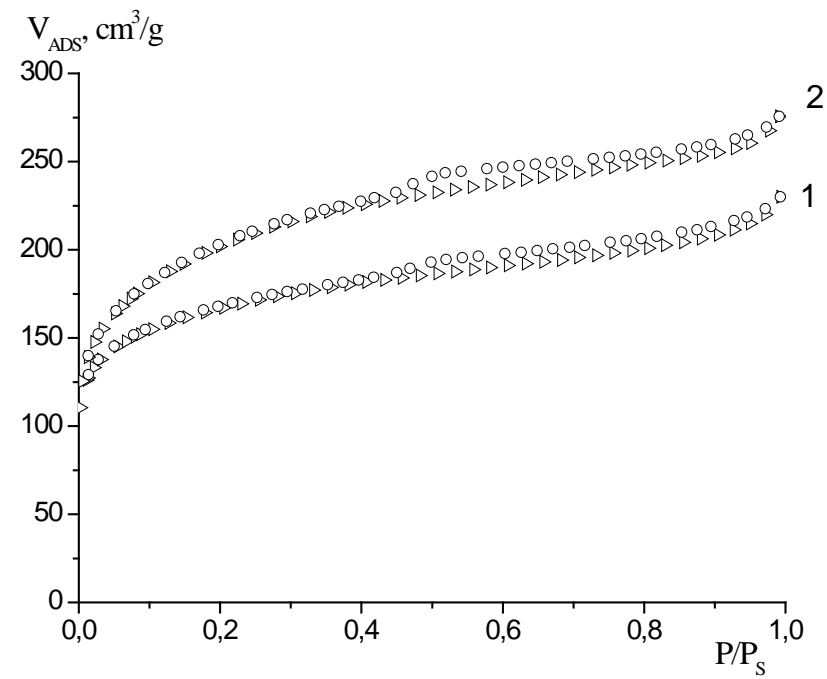

Figure 2. Adsorption and desorption isotherm of nitrogen at $77 \mathrm{~K}$ for initial active carbon AG-5 (1) and oxidized sample AG-5ox (2).
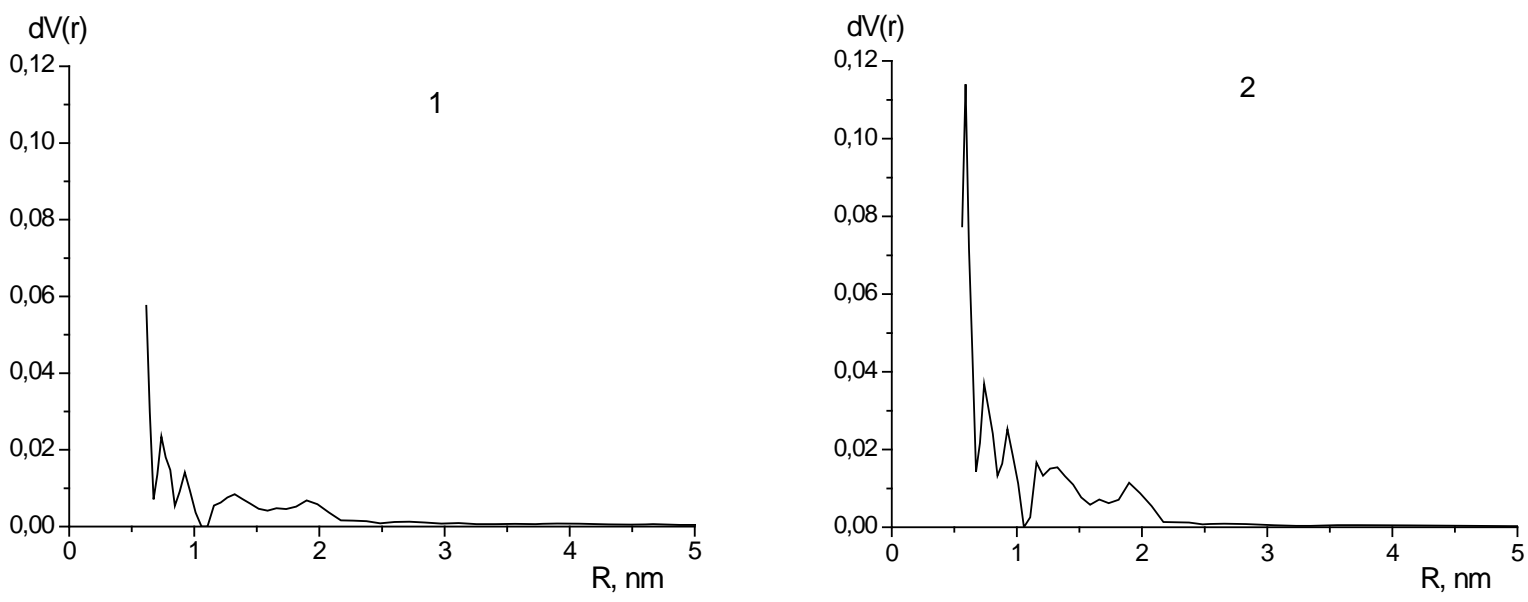

Figure 3. Pore size distribution using NLDFT method for active carbon samples: (1)- AG-5; (2)- AG-5ox.

Table 4

Parameters of porous structure determined from nitrogen adsorption isotherms.

\begin{tabular}{lcccccc}
\hline Sample & $\begin{array}{l}S_{B E T}, \\
\mathrm{~m}^{2} / \mathrm{g}\end{array}$ & $\begin{array}{c}V_{\text {total }}, \\
\mathrm{cm}^{3} / \mathrm{g}\end{array}$ & $\begin{array}{c}V_{\text {meso }} \\
\mathrm{cm}^{3} / \mathrm{g}\end{array}$ & $\begin{array}{c}V_{\text {micro }} \\
\mathrm{cm}^{3} / \mathrm{g}\end{array}$ & $\begin{array}{c}R_{\text {micro }}, \\
\mathrm{nm}\end{array}$ & $\begin{array}{c}E_{\text {micro }} \\
\mathrm{kJ} / \mathrm{mol}\end{array}$ \\
\hline AG-5 & 611 & 0.36 & 0.09 & 0.27 & 1.08 & 12.07 \\
AG-50x & 717 & 0.43 & 0.11 & 0.32 & 1.11 & 11.72 \\
\hline
\end{tabular}

$S_{B E T}$ - surface area determined by Brunauer-Emmet-Teller equation;

$V_{\text {total }}$ - total pore volume;

$V_{\text {meso }}$ - mesopore volume;

$V_{\text {micro }}$ - micropore volume;

$R_{\text {micro }}$ - average micropore radius;

$E_{\text {micro }}$ - adsorption energy in micropores. 
Thermo-gravimetric analysis (TGA) and derivative thermo-gravimetric (DTG) curves of active carbon samples are presented in Figures 4 and 5. TGA curve of the oxidized sample AG-5ox differs from that of unmodified sample AG-5, which indicates that the oxidation with concentrated nitric acid has changed not only the surface properties, but also destroyed the active carbon structure making its decomposition much easier. TGA and DTG curves of the two samples show an initial weight loss around $100^{\circ} \mathrm{C}$, which is related to thermodesorption of physically adsorbed water [13, 21, 22]. The weight loss at $250^{\circ} \mathrm{C}$ is presented only on the DTG profile of the oxidized sample (AG-5ox) being attributed by many researchers to the decomposition of carboxylic surface groups [23-25]. Till around $400{ }^{\circ} \mathrm{C}$ the decomposition of lactonic and phenolic groups takes place [23-25] and then the active carbon sample buns out (Figure 5). The unmodified sample, AG-5, is much more thermally stable in comparison with oxidized sample (Figure 4). The DTG profile of this sample does not present any significant weight loss until $450^{\circ} \mathrm{C}$. Both samples present ash content at $1000^{\circ} \mathrm{C}$ much high for AG-5, about 16\% (Figure 4).

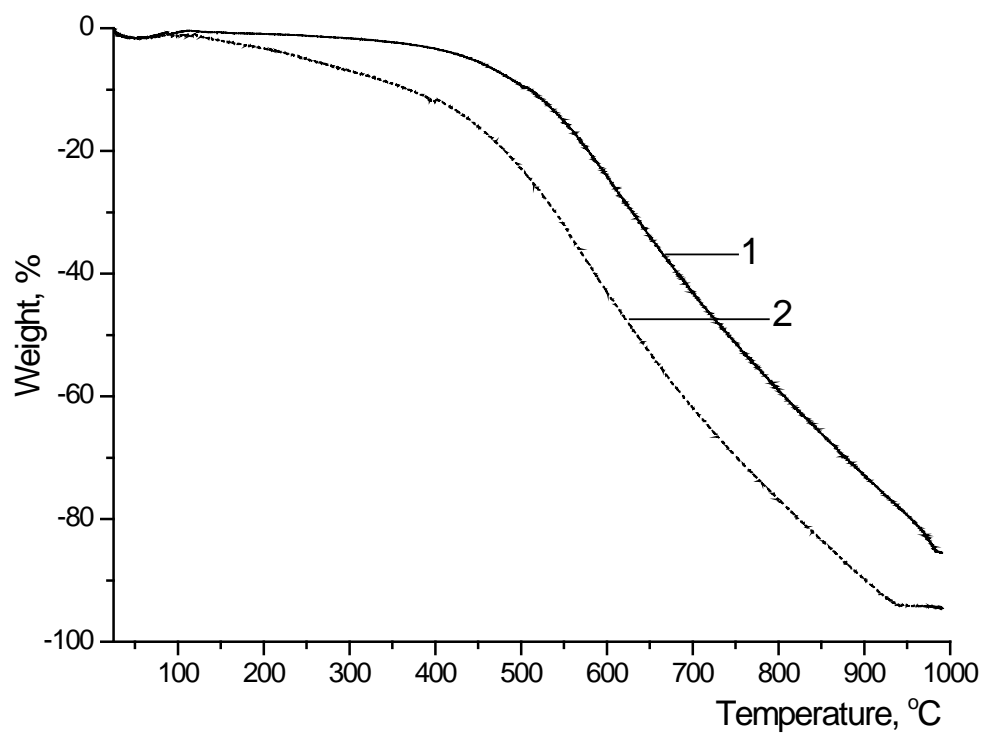

Figure 4. TGA curves measured in air for unmodified AG-5 (1) and oxidized AG-5ox (2) samples.

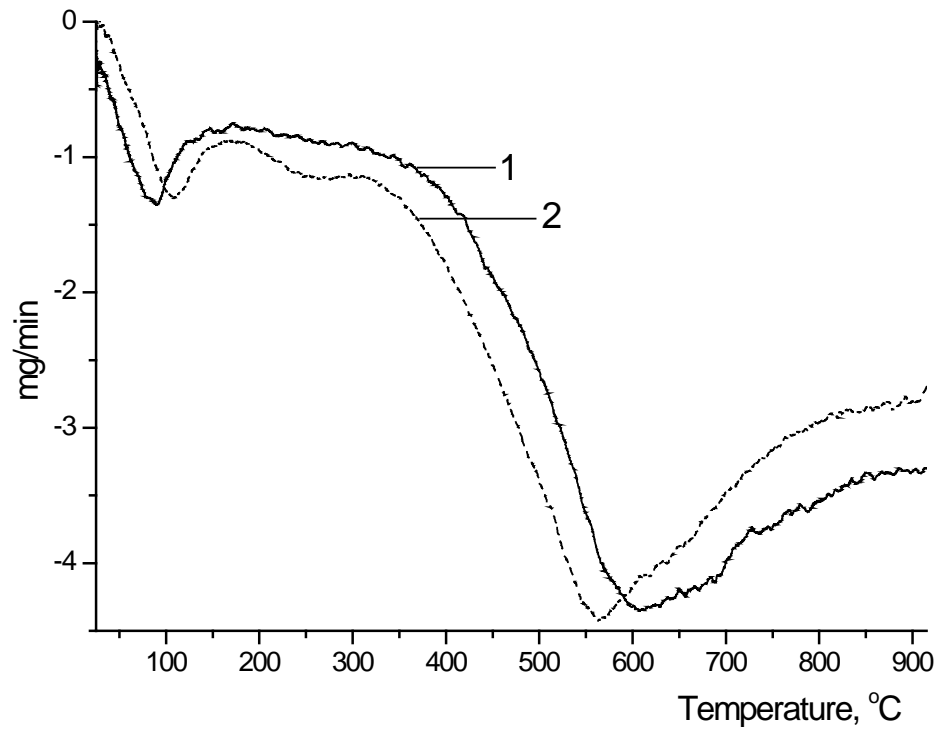

Figure 5. DTG curves for unmodified AG-5 (1) and oxidized AG-5ox (2) samples. 


\section{Surface chemistry characteristics}

The surface properties of the active carbons were evaluated by $\mathrm{pH}$ of the carbon surface, Boehm titration method and spectral analysis under IR range.

The results of Boehm's titration method and $\mathrm{pH}$ value of the carbon surface are given in Table 5. Significant differences have existed on the amount of acidic and basic functional groups of the active carbons. After oxidation process with nitric acid the surface of AG-5ox sample becomes acidic and pH of active carbon suspension decrease till 3.30.

The amount of total acidic groups (titrated with $\mathrm{NaOH}$ ) on active carbon surface AG-5ox increases by about 6 times and strong acidic groups - by about 9 times in comparison with initial sample AG-5. At the same time the amount of basic groups decreases by about 4 times (Table 5). The concentration of the acidic groups on the active carbon surface (AG-50x) was in the following order: strong acidic >>> weak acidic > phenolic.

Table 5

Surface chemistry of active carbons samples evaluated by Boehm method and pH of suspension.

\begin{tabular}{|c|c|c|c|c|c|c|c|c|c|}
\hline \multirow{3}{*}{ Sample } & \multirow[b]{3}{*}{$\begin{array}{c}\text { pH of } \\
\text { suspension }\end{array}$} & \multicolumn{4}{|c|}{$\begin{array}{l}\text { Quantity of the functional groups. } \\
\text { Amount, } \mathrm{meq} / \mathrm{g}\end{array}$} & \multicolumn{4}{|c|}{$\begin{array}{c}\text { Character of the functional groups. } \\
\text { Amount, meq } / \mathrm{g}\end{array}$} \\
\hline & & \multicolumn{4}{|c|}{ Titrant } & \multicolumn{2}{|c|}{ Carboxylic } & \multirow[b]{2}{*}{ Phenolic } & \multirow[b]{2}{*}{ Basic } \\
\hline & & $\begin{array}{l}0.05 \mathrm{~N}_{2} \\
\mathrm{NaHCO}_{3}\end{array}$ & $\begin{array}{l}0.05 \mathrm{~N} \\
\mathrm{Na}_{2} \mathrm{CO}_{3}\end{array}$ & $\begin{array}{l}0.05 \mathrm{~N} \\
\mathrm{NaOH}\end{array}$ & $\begin{array}{l}0.05 N \\
\mathrm{HCl}\end{array}$ & $\begin{array}{l}\text { Strong } \\
\text { acidic }\end{array}$ & $\begin{array}{l}\text { Weak } \\
\text { acidic }\end{array}$ & & \\
\hline AG-5 & 6.65 & $\begin{array}{c}0.16 \\
\pm 0.02\end{array}$ & $\begin{array}{c}0.22 \\
\pm 0.02\end{array}$ & $\begin{array}{c}0.38 \\
\pm 0.01\end{array}$ & $\begin{array}{c}0.48 \\
\pm 0.03\end{array}$ & 0.16 & 0.06 & 0.16 & 0.48 \\
\hline AG-50x & 3.30 & $\begin{array}{r}1.48 \\
\pm 0.02 \\
\end{array}$ & $\begin{array}{r}1.99 \\
\pm 0.02 \\
\end{array}$ & $\begin{array}{r}2.33 \\
\pm 0.01 \\
\end{array}$ & $\begin{array}{c}0.13 \\
\pm 0.02 \\
\end{array}$ & 1.48 & 0.51 & 0.34 & 0.13 \\
\hline
\end{tabular}

The FTIR spectral analysis is an important tool to identify some characteristic functional groups on the active carbons surface. In Figure 6 the IR spectra for active carbons AG-5 and AG-5ox are compared. For both of the activated carbons, before and after oxidation, there are a number of common bands. The absorptions around $800 \mathrm{~cm}^{-1}$ are assigned to the out of plane bending of the ring $\mathrm{C}-\mathrm{H}$ bonds [25-27].

Bands in the 1000-1200 $\mathrm{cm}^{-1}$ region are difficult to assign because there is a superposition of a number of broad overlapping bands. It could be assign to C-O as in phenols/ethers/esters $(1200 \mathrm{~cm})$ [9, 27]. The shoulder at $1164 \mathrm{~cm}^{-1}$, together with two absorptions of low intensity (1385 and $1399 \mathrm{~cm}^{-1}$ ), confirm the presence of phenolic groups on the oxidized active carbon surface (AG-5ox, Figure 5 (2)).

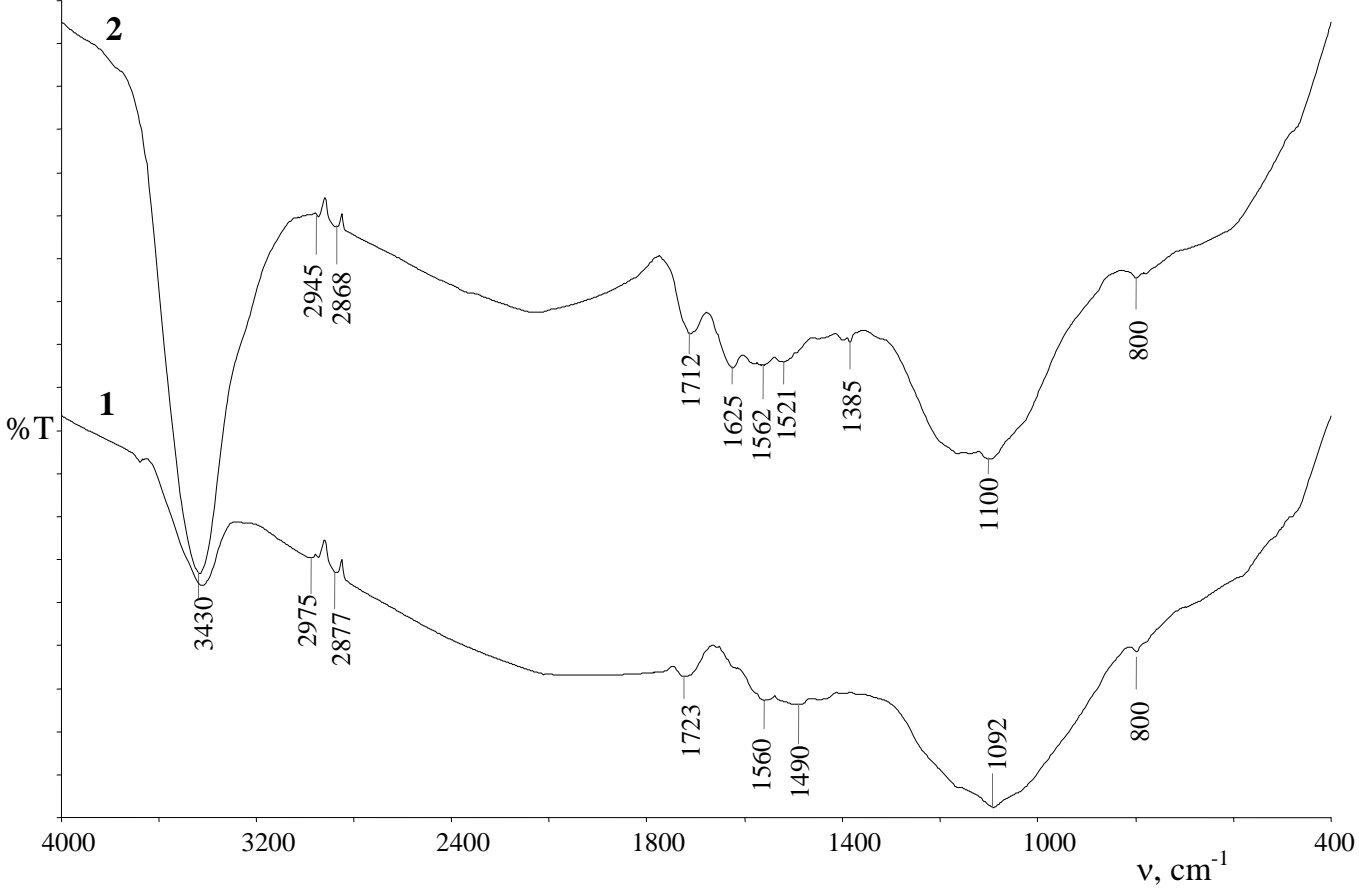

Figure 6. FTIR spectra of the initial activated carbon AG-5 (1) and oxidized with nitric acid AG-5ox (2). 
The bands in the region of 1500-1600 $\mathrm{cm}^{-1}$ have been observed by many authors and have not been interpreted unequivocally. These bands, presented in the spectrum of AG-5ox at 1521, 1562 and $1625 \mathrm{~cm}^{-1}$, and in the spectrum of AG-5 at 1490 and $1560 \mathrm{~cm}^{-1}$, can be assigned to aromatic ring stretching $(\mathrm{C}=\mathrm{C})$ coupled to highly conjugated carbonyl groups $(\mathrm{C}=\mathrm{O})[24,26]$.

The band between 1700 and $1730 \mathrm{~cm}^{-1}$, that can be assigned to the stretching vibration of $\mathrm{C}=\mathrm{O}$ bonds, characteristic of carboxylic, ketone and aldehide groups [11, 24] is much higher in AG-5ox than in AG-5 spectrum.

In the region 2860-2980 $\mathrm{cm}^{-1}$, two bands of low intensity are presented, frequently attributed to aliphatic $\mathrm{CH}$ bond in the $\mathrm{CH}, \mathrm{CH}_{2}$ and $\mathrm{CH}_{3}$ groups [26].

Broadband in the region $3300-3600 \mathrm{~cm}^{-1}$ is assigned to (OH stretching) vibrations of $\mathrm{OH}$ groups of related alcohols, phenols and carboxylic acids [11, 26, 27].

Generally, used methods to quantify the surface characteristic groups on active carbon samples show an increase of acidic surface groups on oxidized sample, presented as strong acidic - carboxylic groups, weak acidic - ketones and aldehide groups, and phenolic groups.

\section{Conclusions}

Evaluation of physical-chemical and surface chemistry characteristics of unmodified and oxidized active carbon samples indicates that oxidation with concentrated nitric acid changed not only the surface properties but also destroyed the active carbon structure making its decomposition much easier. The unmodified sample, AG-5, is much more thermally stable in comparison with oxidized sample (AG-5ox).

The slight increase of structural parameters $\left(S_{B E T}, V_{\text {total }}, V_{\text {micro }}\right)$ after oxidation treatment with about $14-16 \%$ is due to dissolution of inorganic species that may block the entrance of micropores.

After oxidation process with nitric acid, the surface of AG-5ox sample becomes acidic and $\mathrm{pH}$ of active carbon suspension decreases till 3.30. The amount of total acidic groups on active carbon surface AG-5ox increases by about 6 times in comparison with initial sample AG-5. The obtained results show an increase of acidic surface groups on oxidized sample, presented as strong acidic - carboxylic groups, weak acidic - ketones and aldehide groups, and phenolic groups.

\section{Acknowledgements}

I wish to express the deep appreciation to my supervisor Corresponding member, Professor Tudor Lupascu for his guidance and encouragement during the performed researches.

\section{References}

1. Kawamura, S. Integrated design of water treatment facilities. John Wiley \& Sons: New York, 1991, 658 p.

2. Lupascu, T. Active carbons from vegetable raw materials. Stiinta: Chisinau, 2004. 224 p. (in Romanian).

3. Timbaliuc, N.; Lupascu, T. The influence of the porous structure of local activated carbons on the immobilization of the congo red dye and vitamin B12. Chemistry Journal of Moldova, 2013, 8(1), pp. 90-94.

4. Lupascu, T.; Ciobanu, M.; Botan, V.; Gromovoy, T.; Cibotaru, S.; Petuhov, O.; Mitina T. Study of hydrogen sulfide removal from grundwater. Chemistry Journal of Moldova, 2013, 8(1), pp. 37-42.

5. Tarkovskaja, I.A. Oxidized carbon. Naukova dumka:Kiev, 1981, 200 p. (in Russian).

6. Farberova, E.A.; Vinogradova, A.V.; Shergina, E.S. Development of modified carbonaceous adsorbent for water treatment. Vestnik Permskogo Nacional”nogo Issledovatel”skogo Politehnicheskogo Universiteta. Himicheskaja Tehnologija i Biotehnologija, 2010, 11, pp. 22-30 (in Russian).

7. Moreno-Castilla, C.; Ferro-Garcia, M.A.; Joly, J.P.; Bautista-Toledo, I.; Carrasco-Marin, F.; Rivera-Utrilla, J. Activated carbon surface modifications by nitric acid, hydrogen peroxide, and ammonium peroxydisulfate treatments. Langmuir, 1996, 11, pp. 4386-4392.

8. Vivo-Vilches, J.F.; Bailon-Garcia, E.; Perez-Cadenas, A.F.; Carrasco-Marin, F.; Maldonado-Hodar, F.J. Tailoring the surface chemistry and porosity of activated carbons: Evidence of reorganization and mobility of oxygenated surface groups. Carbon, 2014, 68, pp. 520-530.

9. Moreno-Castilla, C.; Lopez-Ramon, M.V.; Carrasco-Marin, F. Changes in surface chemistry of activated carbons by wet oxidation. Carbon, 2000, 38, pp. 1995-2001.

10. Al-Qodah, Z.; Shawabkah, R. Production and characterization of granular activated carbon from activated sludge. Brazilian Journal of Chemical Engineering, 2009, 26(1), pp. 127-136.

11. Nastas, R.; Rusu, V.; Giurginca, M.; Meghea, A.; Lupascu, T. Alteration of chemical structure of the active vegetal coals. Revista de Chimie (Bucharest), 2008, 59(2), pp. 159-164 (in Romanian).

12. Kuzin, I.A.; Strashko, B.K.; Mironenko, V.M.; Zarubin, O.V. Oxidation of active carbons with nitric acid. Ionnyj obmen i ionity. Nauka: Leningrad, 1970, pp. 178-181 (in Russian).

13. Choma, J.; Jaroniec, M.; Burakiewicz-Mortka, W.; Klinik, J.; Olejniczak, K. Structural and surface properties of active carbons oxidized with nitric acid at high temperature. Polish Journal of Chemistry, 1998, 72(5), pp. 860-868. 
14. Sontheimer, H.; Crittenden, J.C.; Summers, R.S. Activated Carbons for Water Treatment. DVGW-Rorschungsstelle: Karlsruhe, 1988, 722 p.

15. Characteristics of the activated carbon AG-5. http://mtksorbent.ru/ugol-aktivnyj-aktivirovannyj/ugli-aktivnye-nakamennougolnoj-osnove/ugol-aktivnyj-ag-5-detail.

16. STAS 5388-80. Vegetable active carbon. Tests methods. Editura Tehnica: Bucuresti, 1980, 18 p. (in Romanian).

17. Cibotaru, S. Study of processes of activated carbon obtaining from wood charcoal. Chemistry Journal of Moldova, 2012, 7(2), pp. 93-97.

18. Autosorb AS-1. AS1Win. Gas Sorption System. Operation Manual. Firmware: version 2.55. AS1Win Software: version 2.0 and newer. Quantachrome Instruments, 2008.

19. Tcaci, M.; Himcinschi, C.; Nastas, R.; Petuhov, O.; Lupascu, T.; Zahn, D.R.T. Non-destructive characterization of modified activated carbon. Revista de Chimie (Bucharest), 2011, 62(7), pp. 727-731.

20. Boehm, H.P. Chemical identification of surface groups. In Advances in Catalysis. Academic Press: New York, 1966, 16, pp. 179-274.

21. Li, Z.; Jaroniec, M.; Choma, J. Thermogravimetric and adsorption studies of oxidized active carbons by using different probe molecules. Thermochimica Acta, 2000, 345, pp. 165-72.

22. Maroto-Valer, M.M.; Dranca, I.; Clifford, D.; Lupascu, T.; Nastas, R.; Leon y Leon, C.A. Thermal regeneration of activated carbons saturated with ortho- and meta-chlorophenols. Thermochimica Acta, 2006, 444 pp. 32-40.

23. Figueiredo, J.L.; Pereira, M.F.R.; Freitas, M.M.A.; Órfão, J.J.M. Modification of the surface chemistry of activated carbons. Carbon, 1999, 37(9), pp. 1379-1389.

24. Radovic, L.R. Ed. Chemistry \& Physics of Carbon. CRC Press, 2008, 30, 264 p.

25. Bingzheng, L. Characterization of pore structure and surface chemistry of activated carbons - A Review. In Salih, S. Ed. Fourier Transform - Materials Analysis. InTech, 2012, pp. 165-190. Available from: http://www.intechopen. com/books/fourier-transform-materials-analysis/charaterization-of-porestructure-and-surface-chemistry-ofactivated-carbons-a-review.

26. Zawadzki, J. Infrared spectroscopy in surface chemistry of carbons. In Thrower, P.A. Ed. Chemistry and Physics of Carbon. Marcel Dekker: New York, 1989, 21, pp. 147-380.

27. Akolekar, D.B., Bhargava, S.K. Influence of thermal, hydrothermal, and acid-base treatments on structural stability and surface properties of macro- meso-, and microporous carbons. Journal of Colloid and Interface Science, 1999, 216(2), pp. 309-319. 